\title{
USE INTERACTIVE MEDIA TO ENHANCE CREATIVITY OF DESIGNERS BY STIMULATING THE SENSES IN THE CONTEXT OF ART DESIGN EDUCATION
}

\author{
Liu, Xiaoxiao (1,2); \\ Nagai, Yukari (1); \\ Yabuuchi, Kumi (1); \\ Cui, Xiuxia (1,3) \\ 1: Japan Advanced Institute of Science and Technology; \\ 2: National Demonstration Center for Experimental Fashion Design and Engineering Education, \\ Dalian Polytechnic University, Dalian, China; \\ 3: School of Foreign Languages Dalian Polytechnic University
}

\begin{abstract}
Creativity is very important for designers, and methods to stimulate designers' creativity are the longterm focus of art design education. The senses are an important channel for designers to receive information and define core issues. Stimulating the designer's senses can help enhance their perception and creativity, and is of great benefit for the quality and efficiency of the design outcome. Today's interactive media technology provides more possibilities and advantages for designers' perception and sensation. The purpose of this research is to explore a way to stimulate the designer's senses through the use of interactive media, thereby improving the designer's design thinking and creativity, and providing designers with innovative design support. By means of interactive ground projection and experiments, and discussion of the advantages of interactive media to stimulate designers' senses, this research proposes innovations in art design educational media, which is valuable for the training and learning of designers and the development of virtual education environment in the future.
\end{abstract}

Keywords: Creativity, Design process, Virtual reality, Senses, Art Design Education

\section{Contact:}

Liu, Xiaoxiao

Japan Advanced Institute of Science and Technology

School of Knowledge Science

Japan

s1920042@jaist.ac.jp

Cite this article: Liu, X., Nagai, Y., Yabuuchi, K., Cui, X. (2021) 'Use Interactive Media to Enhance Creativity of Designers by Stimulating the Senses in the Context of Art Design Education', in Proceedings of the International Conference on Engineering Design (ICED21), Gothenburg, Sweden, 16-20 August 2021. DOI:10.1017/pds.2021.593 


\section{BACKGROUND}

Viktor Lowenfeld believes that the purpose of art education is to make people more creative in the creative process. The essence of design is creativity, and creativity comes from creative thinking. The key to art design education is to stimulate the creative thinking of designers and to strengthen the creative thinking and methods that are closely related to innovative design, which is the basis for cultivating excellent creative capabilities.

Under the influence and penetration of the artificial intelligence (AI) research wave, the field of education is changing. On the one hand, the combination of artificial intelligence and learning science (LS) has formed a new field: educational artificial intelligence (EAI). On the other hand, the innovation and development of education have become an inevitable trend in the information age.

The characteristics of interactive media provide new support for stimulating the creativity of designers. Interactive media combines different computer technologies to sort text information, videos, pictures, etc., in a timely manner and integrates the applicational effects of multimedia technology to make the information presented more diverse, beautiful, and easy to obtain (Liu, 2020). The development of interactive media that supports sensory stimulation is essential to enhance the creativity of designers. Particularly, virtual interactive objects, textures, and interactive sounds have huge potential in art design education.

\section{RELATED WORK AND DEFINITIONS}

\subsection{Creativity and Designer}

Designers must be creative to face the challenge of the future, and education pays more and more attention to creativity. The terms "creativity and creative thinking" are closely linked and can be used interchangeably, creativity usually comes from creative thinking (Corazza \& Agnoli, 2016). Therefore, many scholars (Al-Oweidi, 2013, Castro, 2011, Cramond, 2015, Demir and Isleyen, 2015, Garaigordobil and Berrueco, 2011, Miller and Dumford, 2015) focus on creative thinking to cultivate creativity, especially in an educational environment.

Creativity is described as the process of creating novel and effective ideas, artifacts, processes, and solutions (Cropley, 2003; Fox and Fox, 2000; Oldham and Cummings, 1996; Zhou and George, 2001). Therefore, creative thinking is the key to the design process.

\subsection{Design thinking and process}

Design can be described as the most creative human force (Nagai, 2015). Pendleton-Jullian and Brown believe that design thinking ability is the core quality of creativity in the 21 st century. The term "design thinking" refers to the cognitive process of design work (Cross, 2011, Simon, 1969), or the thinking skills and practices used by designers to create new artifacts or ideas and solve practical problems.

Design is the creative process of intentionally developing something that does not yet exist (Kelley \& Kelley, 2013). The designer's work is repeated and often characteristic, but the designer's creativity and design strategy are influenced by the process and information provided (Buchanan, 2001). These design thinking techniques provide flexible support and foundation for an open creative practice stage (Hoadley and Cox, 2009; Watson, 2015).

The Hasso-Plattner Institute of Design at Stanford (d. School) proposed the IDEO Design Thinking Model as a five-stage design thinking model. d.school is a first-class university that teaches design thinking. The five stages of design thinking they propose are: Empathize, Define, Ideate, Prototype, and Test.

Judging from the IDEO Design Thinking Model, the design thinking process can be summarized into three core links: observe design challenges, establish a connection between ideas and solutions, reflect and improve the design. The phase of observing the design challenge includes empathy and definition, and conception is also the process of connecting ideas and solutions. Designers often use prototypes to test their designs, reflect on, and improve the designs (Figure 1).

The design process often starts from the first core link. Empathy is a deep understanding of the problems and reality of the person to be designed. It involves understanding the difficulties users face and discovering their underlying needs and desires to explain their behavior. To do this, a designer 
needs to understand the user's environment and their role in the environment, and their interaction with the environment.

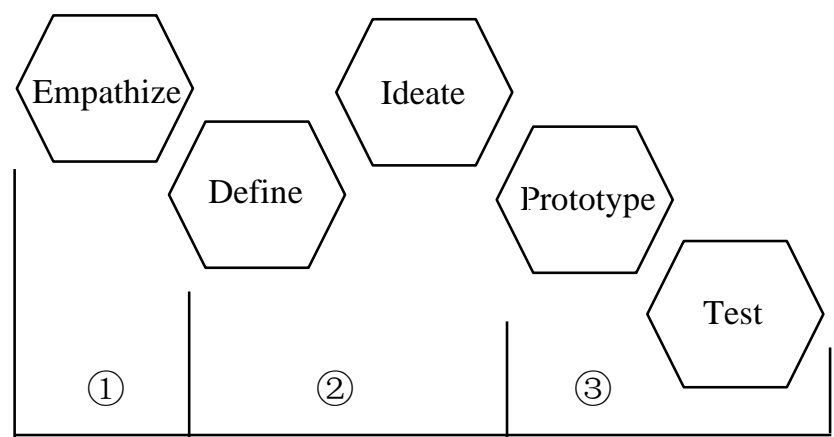

(1) Observe design challenges

(2) Establish a connection between ideas and solutions

(3) Reflect and improve the design

Figure 1. The three core links of the design thinking

\subsection{The five senses and information construction}

The five human senses include sight, smell, hearing, taste, and touch. The physical process by which sensory systems respond to stimuli and provide sensory data is called sensation (Wolfe, Jeremy; Kluender, Keith; Levi, Dennis, 2012). During the sensory process, sensory organs are involved in the collection and conduction of stimuli (Privitera, A. J., 2020).

Japanese designer Kenya Hara proposed that information construction requires multiple channels. The five senses of human beings are considered to be different sensory types, and through their special functions, they construct information correspondingly (Table 1).

Table 1. Information corresponding to sensory types

\begin{tabular}{|l|l|}
\hline Human sensory types & Information corresponding to sensory types \\
\hline Sight & $\begin{array}{l}\text { Information is obtained by visually distinguishing characteristics such as the size, } \\
\text { brightness, color, movement, and shape of objects. }\end{array}$ \\
\hline Touch & $\begin{array}{l}\text { The tactile sensation is produced by touching the body, such as position, pressure, } \\
\text { temperature, surface shape, etc. }\end{array}$ \\
\hline Hearing & $\begin{array}{l}\text { Sound, vibration, ultrasound, acceleration, etc. are felt and analyzed through the } \\
\text { auditory system. }\end{array}$ \\
\hline Taste & $\begin{array}{l}\text { A sense of proximity is transmitted to the brain's nervous system through the } \\
\text { taste bud nerves, such as sweet, sour, bitter, spicy, and salty. }\end{array}$ \\
\hline Smell & $\begin{array}{l}\text { A distant sense, such as smell, is formed by the olfactory nervous system and the } \\
\text { nasal trigeminal nervous system. }\end{array}$ \\
\hline
\end{tabular}

\subsection{Interactive Media and computer-based educational environment}

The educational environment can be divided into a traditional educational environment and a computer-based educational environment (Romero \& Ventura, 2013). The computer-based educational environment includes the virtual learning environment (VLE), learning management system (LMS), Massive Open Online Course (MOOCs), social learning, web-based education, cognitive tutor system, computer education, multi-mode and mobile environment (Papamitsiou \& Economides, 2014).

Interactive media is the application and integration of a variety of advanced technologies and multidisciplinary knowledge. Interactive media technologies include Virtual Reality (VR), Augmented Reality (AR), and Mixed Reality (MR). VR technology uses computer technology to generate realistic visual, auditory, and tactile integration in a specific range of virtual environments. The three characteristics of Virtual Reality (VR) are immersion, interactivity, and imagination, which greatly overcome the limitations of the traditional teaching environment. As such, VR can stimulate learning, create learning situations, enhance the learning experience, feel the psychological immersion, cross the boundaries of time and space, dynamically interact across, and cross-boundary knowledge fusion. VR technology can bring positive emotions to designers, such as relaxation, joy, and interest (Shimeta1, 2003; Limnioueta1, 2008; Huangeta1, 2010), uses multiple channels (such as auditory vision, tactile 
sensation, etc.) can meet the needs of situational learning (Huang \& Liaw., 2011) and thus has the potential of supporting creative thinking.

\section{RESEARCH AIM AND HYPOTHESIS}

The purpose of this research is to propose a combination of interactive media technology and art design education to continuously improve the designer's creativity and release the designer's imagination. The hypothesis is that the use of interactive media technology can stimulate the senses of the designer in multiple ways and this stimulation can further promote the development of designer's creative abilities compared with the existing creative thinking education. Combining art, technology, creativity, and human core abilities can strengthen the designer's creative thinking in new ways.

\section{METHOD}

Four media were used to stimulate the designer's senses, and interactive ground projection was used as a simulation to support virtual interactive media in the early stages of the experimental activities in this study. The interactive ground projection has the characteristics of VR technology and enriches the lines of perception by generating a realistic vision, hearing, and touch in a specific range of virtual environments to meet the needs of stimulating the creativity of designers.

\subsection{Non-interactive design simulation to stimulate the senses of designers}

\subsubsection{Four Seasons Images}

Four images were produced corresponding to the four seasons of spring, summer, autumn, and winter (Figure 2). The image adopts the form of pixel expression and uses different colors to reflect the characteristics of the four seasons. These four images have no concrete forms of objects. Using such an abstract form of expression makes their format and information volume completely consistent, and provides designers with imagination.

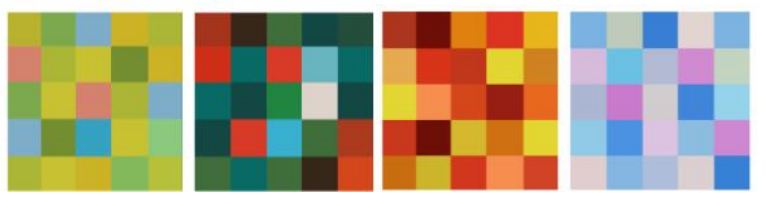

Figure 2. Images corresponding to the four seasons

\subsubsection{Animation of four seasons}

The four images (Figure 2) corresponding to the four seasons of spring, summer, autumn, and winter were used to make the animation. The animation uses the pixel representation and maintains the color of Figure 2, the difference is that the animation presents a dynamic performance for viewing.

\subsubsection{Ground animation projection of four seasons}

The ground projection was produced using animation corresponding to the four seasons of spring, summer, autumn, and winter. The projector suspended on the ceiling projected the animation on the ground to form a ground projection effect. The ground animation projection changed the way participants watched and enlarged the viewing area.

\subsection{Interactive media simulation to stimulate the senses of designers}

\subsubsection{Multi-sensory experience - interactive ground projection "Crossing the four seasons"}

An interactive media program was produced with the four images in Figure 2 as the content. Each pixel in the image has an interactive function, and the interactive program is projected onto the ground. When the participant interacts with the projection area on the ground, the camera recognizes pedestrian movements in real-time and immediately triggers the interactive program. The program will start the graphics in the media library and perform real-time motion capture to dynamically change color patches and trigger sounds. With the change of the color block, the temperature and odor emission instrument of the test site will change. This human-computer interactive ground projection 
will give the experimenter the feelings of different aspects of the four seasons, such as changes in visual color, changes in footstep sounds, changes in olfactory smell, and changes in somatosensory temperature, thus exceeding the limitations of time and space which stimulated the participants' perception ability (Figure 3 ).
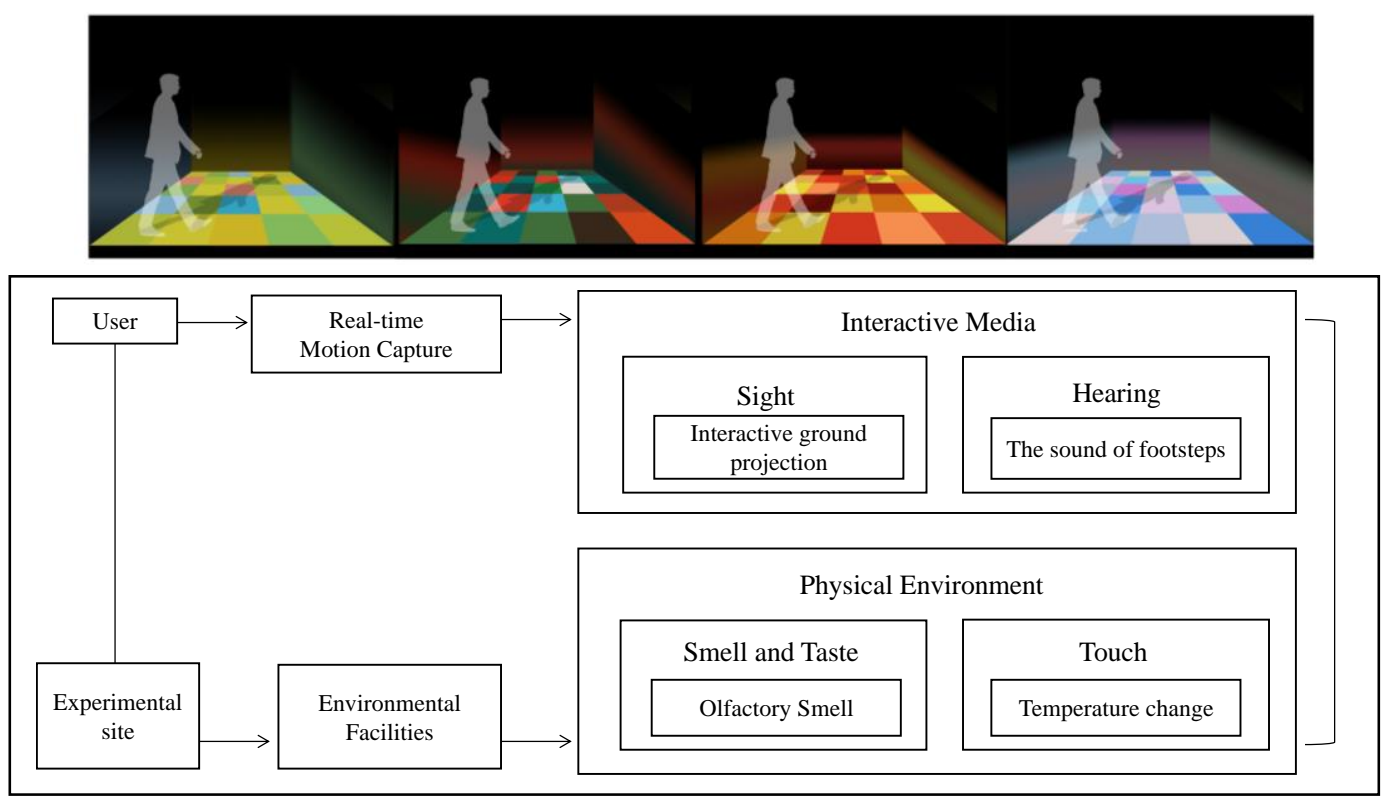

Figure 3. Multi-sensory experience - interactive ground projection "Crossing the four seasons"

\subsubsection{Multi-sensory human-computer interactive ground projection}

The projection is based on human-computer interaction technology and uses Unity.com (interactive 3D development platform) program operation to realize the interaction between human and ground projection images. The system uses the Microsoft Kinect motion capture module to capture human motion and achieve human-computer interaction. It establishes a specific area to capture human activities. Motion recognition and motion capture in this area are performed by the camera. When no user enters the scene, the camera will not have real-time motion recognition and real-time motion capture, the program will not be triggered, and the projection media will not change dynamically. When the user enters the scene, the camera will capture the user's actions in real-time and immediately trigger the interactive program. This program triggers the media library to create real-time dynamic changes to the projected media content.

\subsubsection{Installation conditions}

Interactive projection environment requirements are mainly based on lighting factors. The brightness of the light in the operating environment is directly related to the sensitivity of motion recognition and motion capture. Therefore, during the installation process, the brightness of the environment was adjusted to reduce interference factors. Besides, real-time motion recognition and real-time motion capture area are also needed to debug the installation location. The sensitivity of motion recognition directly affects the accuracy of the following user's footprint. Then, the imaging distance of the projector was closely related to the visual dynamics of media interaction.

\subsubsection{Additional conditions}

This experiment adjusted the temperature of the experimental place to simulate the temperature difference of the four seasons and uses four kinds of fragrances to increase the olfactory information. We tried to control the indoor temperature of the test space and chose four kinds of fragrances, namely grass, floral, fruit, and fresh flavors to correspond to spring, summer, autumn, and winter. 


\section{EXPERIMENT PROCEDURE}

This study invited 16 students from a design school to participate in four experiments. The four experiments are divided into image, animation, ground projection, and human-computer interaction ground projection. These 16 participants joined the experiment one by one, and the order of the experiment was from experiment 1 to experiment 4. The duration of these four experiments was 10 minutes. After completing each set of experiences, the design students were asked to submit design sketches about the theme "Four seasons". The form (color, texture, shape, space, etc.) and amount of design sketches were not limited, but there was a time limit of 30 minutes.

- Experiment 1: Four images were presented on the monitor for 10 minutes.

- Experiment 2: The animation was played on the monitor for 10 minutes.

- Experiment 3: The animation is projected on the ground of the experiment site for 10 minutes.

- Experiment 4: The interactive ground projection "Crossing the four seasons" was run, with a total length of 10 minutes, and additional conditions were artificially manipulated.

\section{EVALUATIONS AND DATA ANALYSIS}

\subsection{Results of Designer's five sense evaluation and data analysis}

Industrial designer Jinsop Lee conducted in-depth research and proposed a set of "Five Senses Theory". He also created a "Five Senses Table" to assess the various sensory feelings, thus scoring each product. In the "Five Senses Table", the vertical axis gradually increases from the origin in the positive direction with a unit of 1 and the score ranges from 0 to 10. The horizontal axis from the origin extends in the positive direction to represent the five sensory feelings of vision, touch, smell, hearing, and taste, respectively. The scores in the "Five Senses Table" can be used intuitively to analyze the level of product design.

After the experiment was completed, the 16 participants were asked to score from 0 to 10 on the fivesense experience of the 4 experiments. Table 2 shows the average value obtained from the five-sense evaluation table of the 16 participants, and Figure 4 presents the same information simultaneously. The four sets of experimental results in the table show very obvious differences. The differences show that interactive media ground projection is superior to non-interactive media ground projection in stimulating the designer's five senses. Especially on the sensations that are difficult to trigger, such as touch, hearing, and smell, the interactive media ground projection presents an evident advantage.

Table 2. The average value obtained from the five-sense evaluation table of 16 participants

\begin{tabular}{|l|l|l|l|l|}
\hline Mean of 16 participants & Experiment 1 & Experiment 2 & Experiment 3 & Experiment 4 \\
\hline Sight & 2.125 & 3.125 & 5.75 & 8.0625 \\
\hline Touch & 0.25 & 0.625 & 2.5 & 5.8125 \\
\hline Hearing & 0.0625 & 0.00 & 0.00 & 5.3125 \\
\hline Smell & 0.375 & 0.75 & 1.3125 & 4.3125 \\
\hline Taste & 0.5 & 0.4375 & 1.375 & 3.5 \\
\hline Sum & 3.3125 & 4.9375 & 10.9375 & 27 \\
\hline
\end{tabular}

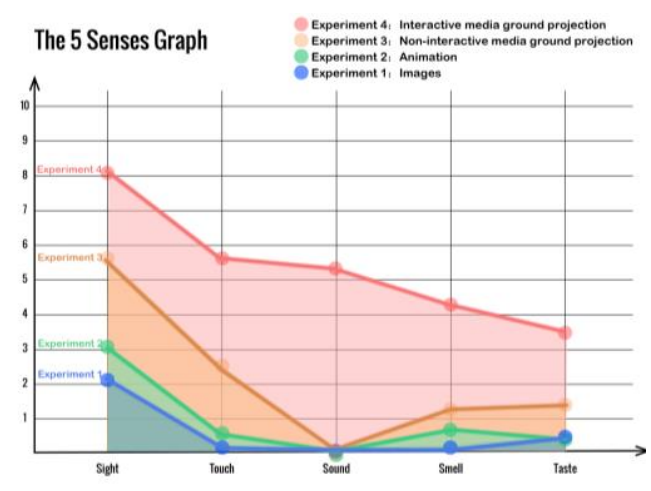

Figure 4. Five sense table about the evaluations. 
Paired t-test analysis was performed to compare the average values of the five senses across the four experimental conditions (Table 3). We found that in the four experiments, the perception of vision has increased, and interactive media has the most significant advantage in vision. In terms of tactility, there is no significant difference between pictures and animations, but there are significant differences between animations and ground projections, and between ground projections and interactive media. In terms of hearing and smell, there is a significant difference between ground projection and interactive media. And in terms of taste, ground projection is better than animation, and interactive media is better than ground projection.

Table 3. Paired samples test

\begin{tabular}{|c|c|c|c|c|c|c|c|c|}
\hline & \multicolumn{5}{|c|}{ Paired Differences } & \multirow[b]{3}{*}{$t$} & \multirow[b]{3}{*}{ df } & \multirow[b]{3}{*}{ Sig. (2-tailed) } \\
\hline & \multirow[b]{2}{*}{ Mean } & \multirow[b]{2}{*}{ Std. Deviation } & \multirow[b]{2}{*}{ Std. Error Mean } & \multicolumn{2}{|c|}{$95 \%$ Confidence Interval of the Difference } & & & \\
\hline & & & & Lower & Upper & & & \\
\hline Pair 1 E1Sight - E2Sight & -1.00000 & .51640 & .12910 & -1.27517 & -.72483 & -7.746 & 15 & $.000 *$ \\
\hline Pair 2 E2Sight - E3Sight & -2.62500 & .88506 & .22127 & -3.09662 & -2.15338 & -11.864 & 15 & $.000 *$ \\
\hline Pair 3 E3Sight - E4Sight & -2.31250 & 60208 & .15052 & -2.63333 & -1.99167 & -15.363 & 15 & $.000 *$ \\
\hline Pair 4 E1Touch - E2Touch & -.37500 & 61914 & .15478 & -.70492 & -.04508 & -2.423 & 15 & .029 \\
\hline Pair 5 E2Touch - E3Touch & -1.87500 & .80623 & 20156 & -2.30461 & -1.44539 & -9.303 & 15 & $.000 *$ \\
\hline Pair 6 E3Touch - E4Touch & -3.31250 & .70415 & .17604 & -3.68772 & -2.93728 & -18.817 & 15 & $.000 *$ \\
\hline Pair 7 E1Hearing - E2Hearing & .06250 & .25000 & .06250 & -.07072 & 19572 & 1.000 & 15 & .333 \\
\hline Pair 9 E3Hearing - E4Hearing & -5.31250 & .70415 & .17604 & -5.68772 & -4.93728 & -30.178 & 15 & $.000 *$ \\
\hline Pair 10 E1Smell - E2Smell & -.37500 & 61914 & .15478 & -.70492 & -.04508 & -2.423 & 15 & .029 \\
\hline Pair 11 E2Smell - E3Smell & -.56250 & 89209 & .22302 & -1.03786 & -.08714 & -2.522 & 15 & .023 \\
\hline Pair 12 E3Smell - E4Smell & -3.00000 & .89443 & .22361 & -3.47661 & -2.52339 & -13.416 & 15 & $.000 *$ \\
\hline Pair 13 E1Taste - E2Taste & .06250 & .57373 & .14343 & -.24322 & .36822 & .436 & 15 & .669 \\
\hline Pair 14 E2Taste - E3Taste & -.93750 & 68007 & .17002 & -1.29989 & -.57511 & -5.514 & 15 & $.000 *$ \\
\hline Pair 15 E3Taste - E4Taste & -2.12500 & 71880 & 17970 & -2.50802 & -1.74198 & -11.825 & 15 & $.000 *$ \\
\hline
\end{tabular}

Sig.<0.01*

\subsection{TTCT test to assess creativity}

Torrance Tests of Creative Thinking (TTCT) is based on the work of JP Guilford and created by Ellis Paul Torrance. The Torrance Creative Thinking Test is a creativity test that initially involves simple tests of divergent thinking and other problem-solving skills. The creativity dimensions of the measurement of TTCT are Fluency, Flexibility, Originality, Elaboration, Resistance to premature closure (Table 4).

In this study, evaluation options were set for these 4 experiments according to the TTCT test dimensions, and 6 design experts were invited to use the 7-level Likert scale to evaluate the sketches of 16 participants (design students).

One-way ANOVA was used to analyze the evaluations of 6 design experts. The result (Table 5) determined that there was a significant difference between the results of the creativity evaluation of the sketches of the 4 experiments $(\mathrm{P}=0.490>0.05)$. Compared with other experiments (Table 6), the interactive media of Experiment 4 has the most obvious advantages (Sig. $=0.000$, Sig. $=0.000$, Sig. $=$ 0.011). In order to discover the kind of advantages, paired t-test was used to analyze the experimental data.

Paired t-test was used to specifically analyze each creativity factor in different experiments (Table 7). The results show that there are significant differences between the four experiments on fluency $($ Sig. $=0.007$, Sig. $=0.002$, Sig. $=0.004)$. In terms of flexibility, ground projection and interactive media show obvious advantages, and interactive media is better than ground projection (Sig. = 0.006, Sig. = 0.001). In terms of originality, both ground projection and interactive media show obvious advantages, and interactive media is better than ground projection (Sig. $=0.001$, Sig. $=$ 0.003). In terms of elaboration and resistance to premature closure, only interactive media showed obvious advantages $($ Sig. $=0.000$, Sig. $=0.001)$. 
Table 4. The creativity dimensions of the measurement of TTCT

\begin{tabular}{|l|l|}
\hline Creativity dimensions & Options \\
\hline Fluency & $\begin{array}{l}\text { The amount of interpretable, meaningful, and relevant ideas generated } \\
\text { in response to the stimulus. }\end{array}$ \\
\hline Flexibility & The number of categories of related conceptions and ideas. \\
\hline Originality & Novelty and uniqueness of conceptions and ideas. \\
\hline Elaboration & The number of details of conceptions and ideas. \\
\hline Resistance to premature closure & Openness and extensibility of conceptions and ideas. \\
\hline
\end{tabular}

Table 5. Test of homogeneity of variances

Evaluation

\begin{tabular}{|c|c|c|c|}
\hline Levene Statistic & df 1 & df2 & Sig. \\
\hline .843 & 3 & 16 & $.490^{*}$ \\
\hline
\end{tabular}

Sig.>0.05*

Table 6. Multiple comparisons

Dependent Variable: Evaluation

LSD

\begin{tabular}{|c|c|c|c|c|c|c|}
\hline \multirow{2}{*}{ (I) Experiment } & \multirow[b]{2}{*}{ (J) Experiment } & \multirow[b]{2}{*}{ Mean Difference (I-J) } & \multirow[b]{2}{*}{ Std. Error } & \multirow[b]{2}{*}{ Sig. } & \multicolumn{2}{|c|}{$95 \%$ Confidence Interval } \\
\hline & & & & & Lower Bound & Upper Bound \\
\hline \multirow[t]{3}{*}{1.00} & 2.00 & .00000 & .29282 & 1.000 & -.6207 & .6207 \\
\hline & 3.00 & $-.65000 *$ & .29282 & $.041^{*}$ & -1.2707 & -.0293 \\
\hline & 4.00 & $-1.48750^{*}$ & .29282 & $.000^{*}$ & -2.1082 & -.8668 \\
\hline \multirow[t]{3}{*}{2.00} & 1.00 & .00000 & .29282 & 1.000 & -.6207 & .6207 \\
\hline & 3.00 & $-65000^{*}$ & .29282 & $.041 *$ & -1.2707 & -.0293 \\
\hline & 4.00 & $-1.48750 *$ & .29282 & $.000^{*}$ & -2.1082 & -.8668 \\
\hline \multirow[t]{3}{*}{3.00} & 1.00 & $.65000^{*}$ & .29282 & $.041^{*}$ & .0293 & 1.2707 \\
\hline & 2.00 & $.65000^{*}$ & .29282 & $.041^{*}$ & .0293 & 1.2707 \\
\hline & 4.00 & $-83750^{*}$ & .29282 & $.011^{*}$ & -1.4582 & -.2168 \\
\hline \multirow[t]{3}{*}{4.00} & 1.00 & $1.48750^{*}$ & .29282 & $.000 *$ & .8668 & 2.1082 \\
\hline & 2.00 & $1.48750 *$ & .29282 & $.000 *$ & .8668 & 2.1082 \\
\hline & 3.00 & $.83750^{*}$ & .29282 & $.011 *$ & .2168 & 1.4582 \\
\hline
\end{tabular}

*. The mean difference is significant at the 0.05 level.

Sig. $<0.05^{*}$

\section{DISCUSSION AND CONCLUSION}

This study verified the hypothesis that interactive media can effectively enhance creativity by stimulating the designer's senses and analyzed the advantages of different media in stimulating different senses. The findings of this study can be helpful to use interactive media to improve art design education in many innovative ways.

\subsection{Interactive media and creativity}

Interactive media can help the creativity of the designer. Designers must consider things from different points of view, and provide new perspectives and effective solutions. This requires designers to perceive the world in a new way, discover hidden patterns, establish connections between unrelated phenomena. Interactive media provides a more comprehensive and innovative perspective of the design object. Compared with the existing design tools, interactive media can provide designers with a new experience and bring new perspectives to the design object, which will help the fluency, 
flexibility, and originality of the design results. Designers can design more meticulously, and their design ideas will be further extended.

\subsection{Interaction media and design thinking}

The first step in the design process is empathy. As a designer, the ability to perceive information is very important. Designers perceive information through their eyes, ears, noses, and mouths, with vision as the most direct sense. With the advent of intelligent technology, interactive media can be used as an important means to stimulate the designer's vision, thereby enhancing the experience of designers to achieve empathy and inspire the designer's creativity. The designer's sense of touch often needs to be stimulated by field experience, but it is often limited by the space and region. Interactive media can achieve tactile sensation by stimulating the skin of designers, providing designers with more possibilities and more diverse experiences to achieve empathy. Hearing stimuli can give designers a deep impression, especially when hearing and vision are combined, designers will get a more lasting and affective empathy. Smell and taste stimuli can enhance the designer's sense of pleasure. Smell and taste can help the designers to reach empathy more directly and quickly, improving the efficiency and quality of design.

\subsection{Dimensional expansion with interactive media}

Designers are more visually aware of things, and often ignore the feedback that the three-dimensional world brings to the human five senses. In interactive media design, one-dimensional interaction is the basis of two-dimensional and multi-dimensional interaction. The one-dimensional interaction is limited to touch, while the two-dimensional interaction implements operations such as sliding and dragging. In three-dimensional space, interactive media design is based on a two-dimensional interactive design incorporating visual, auditory, olfactory, and tactile interactions, and making full use of human manipulation and sensory capabilities to build a three-dimensional space. What designers feel in such a learning environment is no longer a flat object, but a more intelligent interactive environment with touch, smell, and taste. Interactive media technology can achieve communication and interaction across time and space boundaries through virtual scenes to stimulate the senses of designers, improve the perception and learning experience of designers, and promote the integration of designer's knowledge.

Table 7. Paired samples test

\begin{tabular}{|c|c|c|c|c|c|c|c|c|c|}
\hline & & \multicolumn{5}{|c|}{ Paired Differences } & & \multirow[b]{3}{*}{ df } & \multirow[b]{3}{*}{ Sig. (2-tailed) } \\
\hline & & \multirow[b]{2}{*}{ Mean } & \multirow[b]{2}{*}{ Std. Deviation } & \multirow[b]{2}{*}{ Std. Error Mean } & \multicolumn{2}{|c|}{$95 \%$ Confidence Interval of the Difference } & & & \\
\hline & & & & & Lower & Upper & & & \\
\hline Pair 1 & E1Flu - E2Flu & .56250 & .72744 & .18186 & .17488 & .95012 & 3.093 & 15 & $.007^{*}$ \\
\hline Pair 2 & E2Flu - E3Flu & -.75000 & .77460 & .19365 & -1.16275 & -.33725 & -3.873 & 15 & $.002^{*}$ \\
\hline Pair 3 & E3Flu - E4Flu & -.43750 & .51235 & 12809 & -.71051 & -.16449 & -3.416 & 15 & $.004 *$ \\
\hline Pair 4 & E1Fle - E2Fle & -.56250 & 1.15289 & .28822 & -1.17683 & .05183 & -1.952 & 15 & .070 \\
\hline Pair 5 & E2Fle - E3Fle & -.75000 & .93095 & .23274 & -1.24607 & -.25393 & -3.223 & 15 & $.006^{*}$ \\
\hline Pair 6 & E3Fle - E4Fle & -62500 & .61914 & .15478 & -.95492 & -.29508 & -4.038 & 15 & $.001 *$ \\
\hline Pair 7 & E1Ori - E2Ori & 18750 & .54391 & .13598 & -.10233 & 47733 & 1.379 & 15 & .188 \\
\hline Pair 8 & E2Ori - E3Ori & -81250 & .83417 & .20854 & -1.25700 & -.36800 & -3.896 & 15 & $.001 *$ \\
\hline Pair 9 & E3Ori - E4Ori & -.56250 & 62915 & .15729 & -.89775 & -.22725 & -3.576 & 15 & $.003^{*}$ \\
\hline Pair 10 & E1Ela - E2Ela & .25000 & .93095 & .23274 & -.24607 & .74607 & 1.074 & 15 & .300 \\
\hline Pair 11 & E2Ela - E3Ela & -.50000 & 1.09545 & .27386 & -1.08372 & .08372 & -1.826 & 15 & .088 \\
\hline Pair 12 & E3Ela - E4Ela & -1.37500 & 1.08781 & .27195 & -1.95465 & -.79535 & -5.056 & 15 & $.000 *$ \\
\hline Pair 13 & E1Res - E2Res & -.43750 & .81394 & .20349 & -.87122 & -.00378 & -2.150 & 15 & .048 \\
\hline Pair 14 & E2Res - E3Res & -.43750 & .96393 & .24098 & -.95114 & .07614 & -1.815 & 15 & .089 \\
\hline Pair 15 & E3Res - E4Res & -1.18750 & 1.16726 & .29182 & -1.80949 & -.56551 & -4.069 & 15 & $.001 *$ \\
\hline
\end{tabular}

Sig. $<0.01^{*}$ 


\subsection{Interactive media and the learning experience of designer}

The innovative development and application of interactive media technology in future art design education can effectively make up for the shortcomings of traditional teaching models and the limitations of the traditional teaching environment, and provide designers with various forms of digital content and innovative means. The context that combines virtual and real learning environments can enhance the designer's sense of presence and immersion. The excellent interactivity and diversity of interactive media can greatly enhance the designer's interest, enthusiasm, autonomy, and creativity, thereby improving teaching efficiency. Interactive media can combine virtual scenes with the real world, and communicate and interact across time and space boundaries to stimulate the five senses of designer, improve the designer's perception and learning experience, promote the designer's knowledge fusion, and inspire the designer innovative spirit awareness and innovative thinking to cultivate the creativity of designers.

Compared with traditional innovative thinking education, the educational method of using humancomputer interactive media can further promote the development of designer's innovative ability. Most of the previous research on stimulating designer creativity is based on traditional teaching media, and most of their research methods are focused on non-interactive media, such as the design process, design sketches, and design methods. Interactive media integrates the most advanced technology of social technology development and has obvious advantages in art design education.

\section{LIMITATIONS AND FUTURE WORK}

The experimental object of this study is limited, and the factors such as differences in the experimental environment have a certain impact on this study. Also, there are individual differences in the experimental subjects' perceptions of interactive media. Future work will expand the number and scope of experimental subjects, and develop other interactive media forms based on this research, such as VR and AR technology interactive platforms.

\section{ACKNOWLEDGMENTS}

We would like to thank the NEC C\&C Foundation and JAIST Research Grant (Fundamental Research) deeply for their strong support of this research.

\section{REFERENCES}

Agnoli, S., Corazza, G. E., \& Runco, M. A. (2016). "Estimating creativity with a multiple-measurement approach within scientific and artistic domains", Creativity Research Journal, 28(2), 171-176.

Chen, P., Liu, X., Cheng, W., \& Huang, R. (2017). "A review of using Augmented Reality in Education from 2011 to 2016", Innovations in smart learning, 13-18.

Huang, H. M., Rauch, U., \& Liaw, S. S. (2010). “Investigating learners' attitudes toward virtual reality learning environments: Based on a constructivist approach”, Computers \& Education, 55(3), 1171-1182.

Kim, K. H. (2011). Proven reliability and validity of the Torrance Tests of Creative Thinking (TTCT).

Liu, X., Zhao, J., Nagai, Y., \& Yu, M. (2020). "Effective Engineering Design to Make Urban Transportation Systems Perform Brilliantly through Interactive Media", Thirteenth International Tools and Methods of Competitive Engineering Symposium (TMCE 2020), Dublin, Ireland,11-15 May 2020, Delft University of Technology, Proceedings of TMCE 2020, pp.393-402. ISBN/EAN: 978-94-6384-131-3

Liu, X., Kim, E., \& Nagai, Y. (2019). "Design of Affective Experiences Using Interactive Media in the Context of Urban Traffic", KICSS 2019: The 14th International Conference on Knowledge, Information and Creativity Support Systems, Ho Chi Minh City, Vietnam, 21-23 November 2019, Hoa Sen University, Proceedings of KICSS 2019, pp.34-41.

Mei, H. H., \& Sheng, L. S. (2011). "Applying situated learning in a virtual reality system to enhance learning motivation", International journal of information and education technology, 1(4), 298-302.

Nagai, Y., \& Taura, T. (2015). "Studies of design creativity: A review and its prospects", Journal of the Indian Institute of Science, 95(4), 341-351.

Özcan, O., \& Akarun, L. (2002). "Teaching interactive media design”, International Journal of Technology and Design Education, 12(2), 161-171.

Wolfe, J. M., Kluender, K. R., Levi, D. M., Bartoshuk, L. M., Herz, R. S., Klatzky, R. L., ... \& Merfeld, D. M. (2006). Sensation \& perception (pp. 242-245). Sunderland, MA: Sinauer. 